\title{
Effect of physical heating on productivity of cyclic superheated steam stimulation wells
}

\author{
Fengrui Sun ${ }^{1,2,3} \cdot$ Yuedong Yao ${ }^{1,2,3} \cdot$ Guozhen $\mathrm{Li}^{3} \cdot$ Xiangfang $\mathrm{Li}^{2,3}$
}

Received: 2 March 2018 / Accepted: 27 July 2018 / Published online: 2 August 2018

(c) The Author(s) 2018

\begin{abstract}
Previous works have focused on the single factor analysis of the effects of chemical reactions of superheated steam with oil and rock minerals on the oil well productivity. However, the relationship between the factors and the contributions to productivity is still unknown. In this paper, the contribution of physical heating of superheated steam to well productivity is studied with the numerical method. Results show that: (a) the heat in the area has a very limited increase when the temperature of superheated steam continues to increase. (b) At the starting stage, the oil is heated to a higher temperature and the mobility is increased. The elastic energy becomes the dominant factor controlling the productivity of the oil well in the following stage. (c) The chemical reactions of superheated steam with oil and rock minerals are the dominant factors contributing to the productivity.
\end{abstract}

Keywords Cyclic steam stimulation $\cdot$ Numerical model $\cdot$ Contribution to productivity $\cdot$ Physical heating $\cdot$ Chemical reactions

\section{Introduction}

Thermal method has been widely adopted in practical engineering application (Sheikholeslami et al. 2017a, b, c, d, e, f, g, h, 2018a, b, c, d, e, f, g, h). At present, the development of unconventional resources has become a hotspot (Yin et al. 2017, 2018; Zhang et al. 2017a, b, 2018a, b; Feng et al. 2018a, b, c; Hu et al. 2018a, b, c; Shi et al. 2014, 2015a, b, 2018). For the heavy oil industry, thermal fluid injection has been widely adopted (Sun et al. 2017a, b, c; Gao 2018; Huang et al. 2018a, b; Calder et al. 2018). Water heated to

Fengrui Sun

13126682711@163.com

$\triangle$ Yuedong Yao 1181890005@qq.com

$\triangle$ Guozhen Li

1174107928@qq.com

1 State Key Laboratory of Petroleum Resources and Prospecting, China University of Petroleum-Beijing, Beijing 102249, People's Republic of China

2 College of Petroleum Engineering, China University of Petroleum-Beijing, Beijing 102249, People's Republic of China

3 China University of Petroleum-Beijing, Beijing 102249 , People's Republic of China the saturated or superheated state is always selected as the thermal carrier due to both economic and enthalpy factors (Sun et al. 2017d, e, f, g). Saturated steam is the mixture of steam and water under a certain pressure condition (Arab et al. 2018; Struchkov and Rogachev 2018), while superheated steam is completely gas phase (Sun et al. 2017h, i, j). Superheated steam is obtained by continuous heating of saturated steam (Sun et al. 2018a, b, c, d, e, f, g).

It has been reported that, compared with saturated steam, superheated steam has mainly three advantages: (a) heating the reservoir to a higher temperature, (Zhou 2010; Sun et al. 2018h, i, j, k) (b) higher water thermal cracking efficiency, and (c) chemical reaction with rock minerals (Sun et al. 20181, m, n, o, p, q, r, s, t). The first advantage is a physical factor, while the other two are chemical factors. However, at present it is still unknown how these three factors contribute to the recovery of heavy oil.

When it comes to a method of solving a problem, one may adopt the theoretical, experimental or numerical method (Livescu and Craig 2018; Dabirian et al. 2018; Giovani et al. 2018; Babadagli and Cao 2018; Wang et al. 2018; Fu et al. 2018; Fu and Liu 2017a, b; Duan et al. 2018; Wen et al. 2018a, b; Xiong and Wu 2018; Zhang et al. 2018c). At present, the theoretical study on cyclic steam stimulation has encountered the bottleneck. Researchers find it hard to couple the effects of both physical heating and chemical 
reactions into one mathematical model, and then there exists a large calculation error (Yang et al. 2018). The experimental method is able to discover the component change of heavy oil, or the mineral composition change, after steam flooding (Zhou 2010). However, it is hard to make a conclusion of its contribution to heavy oil recovery at field condition. Numerical simulation, on the other hand, is able to make up for this defect, while it cannot couple the chemical reactions into calculation. But, the failure in considering chemical reactions is its advantage. The contribution of physical heating can be studied separately.

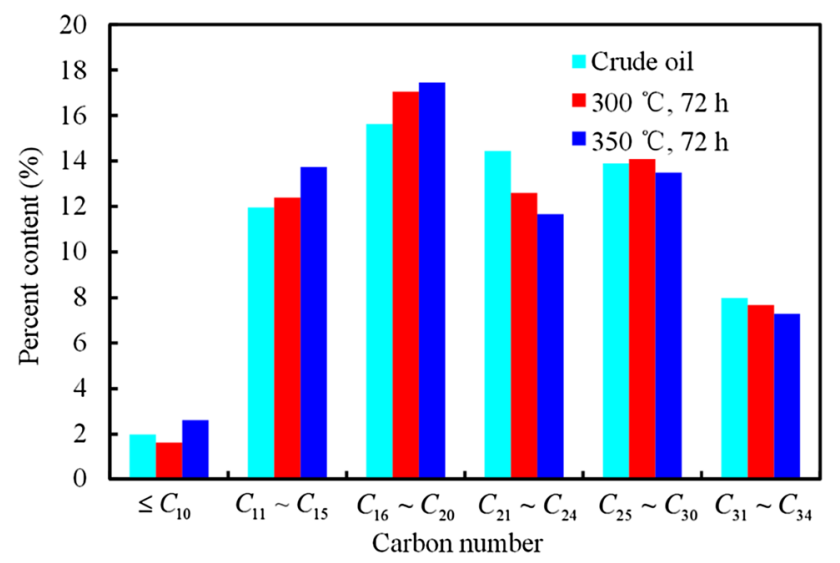

Fig. 1 Transformation of heavy component of heavy oil into light component under superheated steam injection (Zhou et al. 2009)
Permeability change (mD)

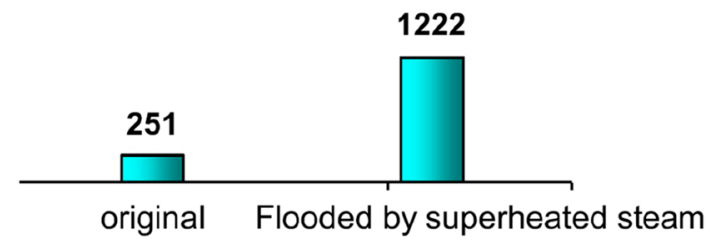

Fig. 3 Increase of the permeability of reservoir (Xu et al. 2013)

In this paper, a numerical model is established to study the contribution of physical heating in the recovery of heavy oil. Then, based on the field data collected from literatures, the contribution of chemical reactions (water thermal cracking of heavy oil and chemical reaction with rock minerals) can be obtained.

\section{Background}

Zhou et al. (2009) conducted a series of experiments on thermal cracking efficiency of heavy oil with superheated steam injection. It is found that, compared with saturated steam injection, the heavy components of heavy oil have high conversion efficiency to light components under superheated steam injection condition, as shown in Fig. 1.
Fig. 2 Comparison of pore structure before and after superheated steam injection using scanning electron microscope (Zhou 2010)
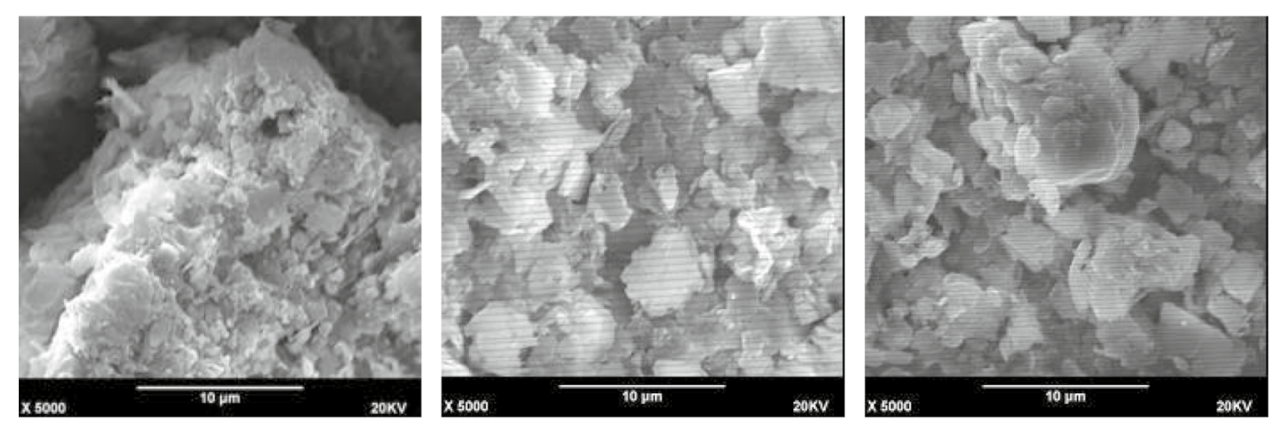

(a) Initial pore structure
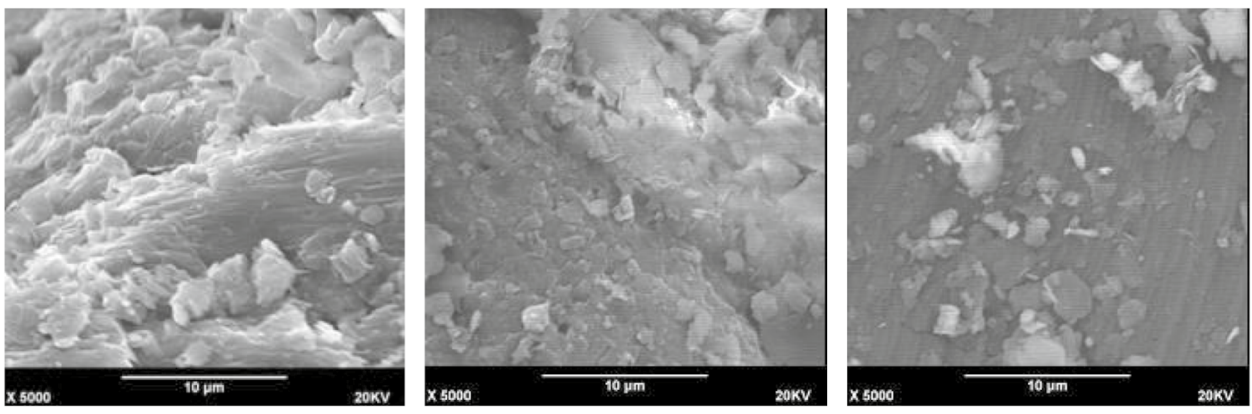

(b) Pore structure after superheated steam injection 


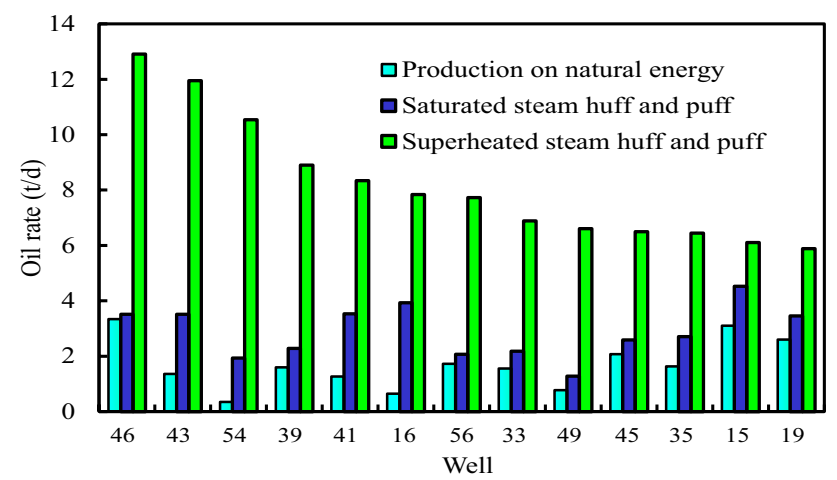

Fig. 4 Numerical model of a cyclic superheated steam stimulation horizontal well

Fig. 5 Basic relationships used in the numerical model
Besides, they also conducted the experiments on the change of rock and mineral composition under superheated steam. The comparison of the pore structure before and after superheated steam injection is shown in Fig. 2 (Zhou 2010). It is found that the clay mineral microcrystallines are richly distributed on the surface of the oil sand particles (Fig. 2a), while the shape and morphology of the clay minerals have been destroyed after superheated steam injection (Fig. 2b).

A further study revealed that the permeability of the rock is increased after superheated steam (as shown in Fig. 3), which also contributes to the increase of productivity.

The above two factors are from the view of chemical reactions. The other main factor influencing the productivity of the cyclic superheated steam wells is the physical heating, which is studied in this paper. One problem that needs to be explained is

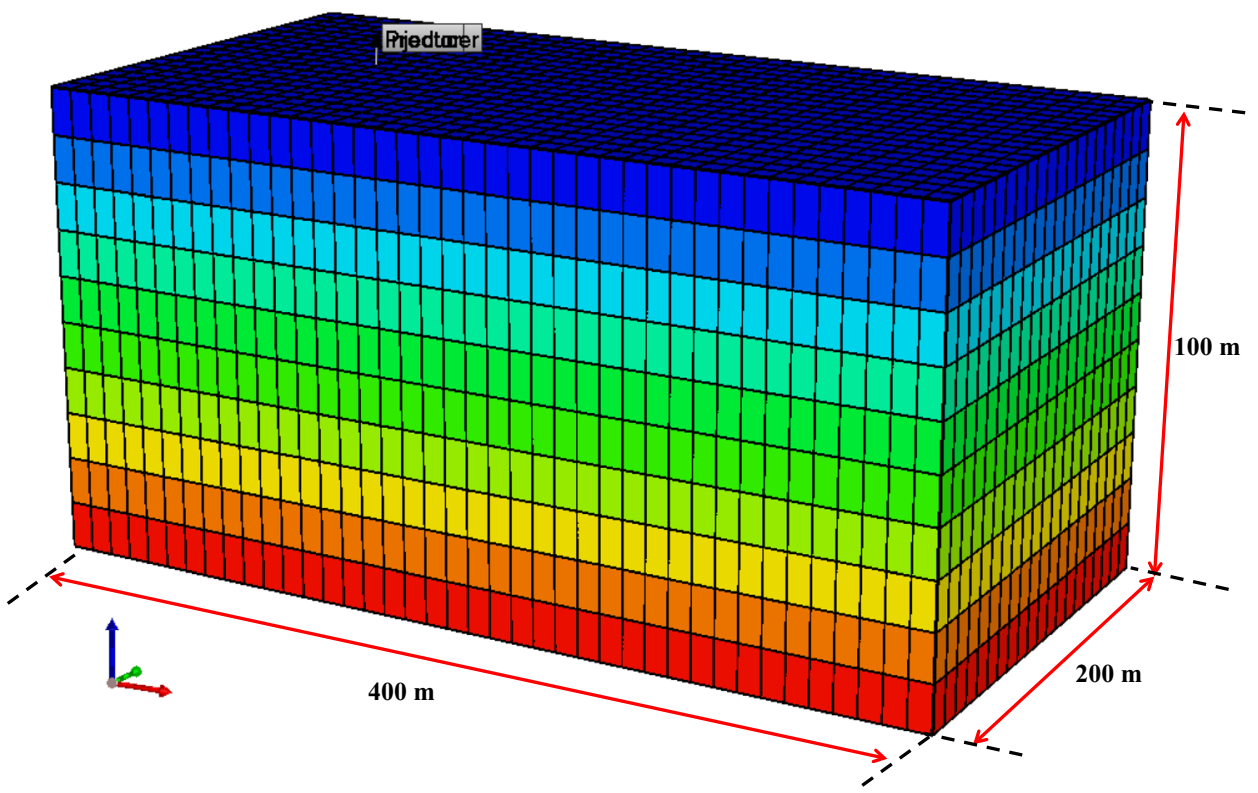

(a) 3-D view of the numerical model

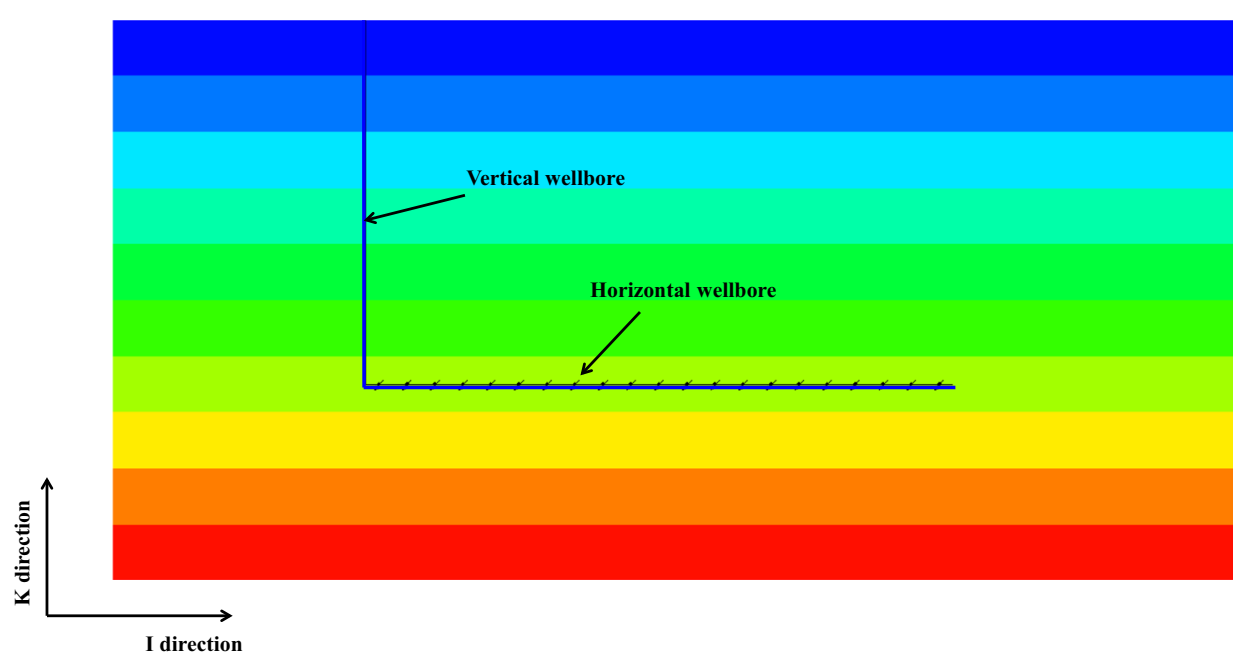

(b) Cross-section of the I-K direction of the numerical model 
the contribution degree of these three factors to the productivity of cyclic superheated steam stimulation wells.

Statistical results showed that, compared with saturated steam injection, the productivity of cyclic superheated steam stimulation wells increases significantly. However, at present, how these factors contribute to this increase is still unknown.

Numerical simulator is an effective tool to study the physical heating effect on productivity because the chemical reactions are neglected.

\section{Numerical model}

A $400 \mathrm{~m} \times 200 \mathrm{~m} \times 100 \mathrm{~m}$ model is built with a horizontal well, as shown in Fig. 4. The initial formation pressure is $2.36 \mathrm{MPa}$. The initial oil saturation is 0.815 . The initial formation temperature is $291 \mathrm{~K}$. The buried depth is $280 \mathrm{~m}$.

The relationship between oil viscosity and temperature, and the relative permeability are shown in Fig. 5.

\section{Discussion}

To capture the key physic of the heating effect on the productivity of cyclic superheated steam stimulation wells, only the first cycle is studied. This is because oil saturation, waste heat, formation pressure and heated radius after several cycles vary from each other. As a result, the productivity of the following cycles are influenced by many factors, and the effect of physical heating is hard to be studied separately. The study of the first cycle has an advantage because of the uniform initial parameters (pressure, temperature and oil saturation, etc.).

The enthalpy of the steam is set as $0.2,0.5,0.8,1.0$ (saturated steam) and $20 \mathrm{~K}$ (superheated steam) with the same value of total mass injection. The temperature distributions in the I-J direction are shown in Fig. 6. It is observed that when the steam is at the saturated state, the heated area increases obviously with increasing steam quality. This is because the enthalpy of steam increases rapidly when the steam quality increases. However, when the steam is at the superheated state, the enthalpy increases slowly with rapid increase of temperature (Zhou 2010; Xu et al. 2013). As a result, the heat in the area has a very limited increase when the temperature of superheated steam continues to increase.

For the process of cyclic steam stimulation, the effect of steam on productivity increase is only obvious at the starting stage of the production period, as shown in Fig. 7 below.

It is observed that at the starting stage (from 50 to 100 days), the gradient of the curve increases with increasing steam quality, while, after 100 days, the gradient of the curve is almost equal to each other. This is because the temperature difference is obvious at the starting stage under different steam state conditions, while the temperature difference

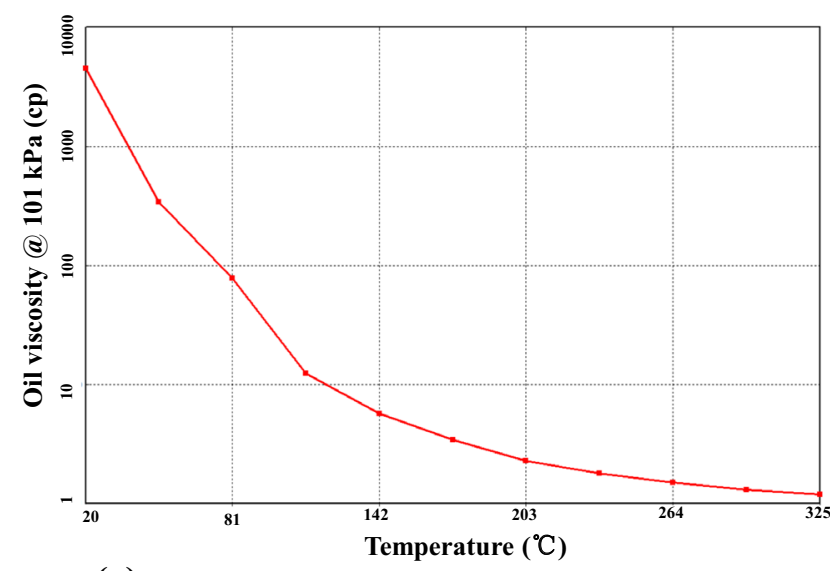

(a) Relationship between oil viscosity and temperature

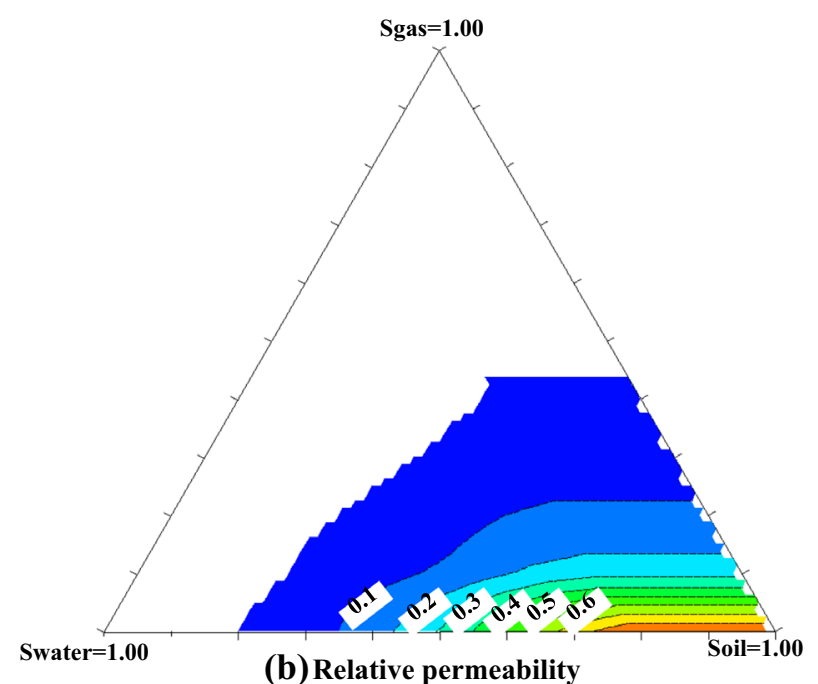

Fig. 6 Comparison of the distributions of temperature when the injection process is finished

becomes small when the heated water and oil are produced. When it is larger than 100 days, the dominant factor controlling the productivity becomes the compressibility of the rock, oil and water. The place initially occupied by heated water and oil are now occupied by cold oil flowing from the faraway places that has not been heated. Second, the pink curve and the blue dotted line coincide. This is a strong evidence that proves the small contribution of physical heating for productivity of cyclic superheated steam stimulation wells. That is to say, the chemical reactions of superheated steam with oil and rock minerals are the dominant factors contributing to the productivity.

Another aspect of the evidence can be found in the daily oil production rate, as shown in Fig. 9 below. It is observed that, from 50 to 100 days, the oil production rate increases rapidly with increasing steam quality. This is because, at the starting stage, the oil is heated to a higher temperature 
Fig. 7 Cumulative oil production under different steam state conditions
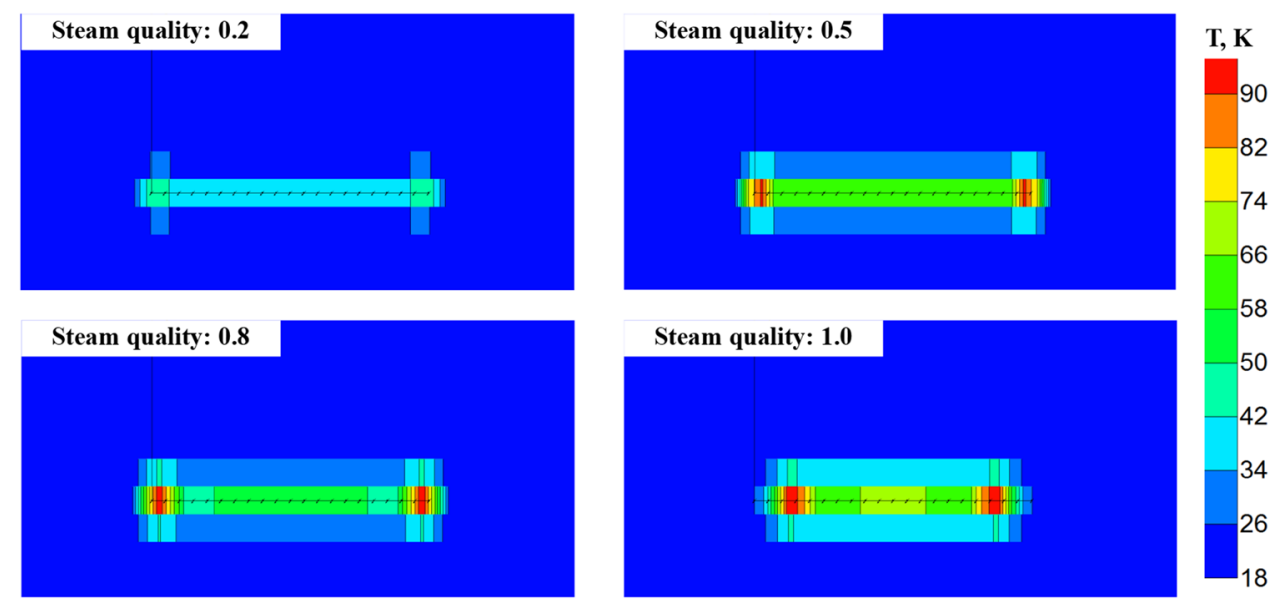

Superheat degree: $20 \mathrm{~K}$

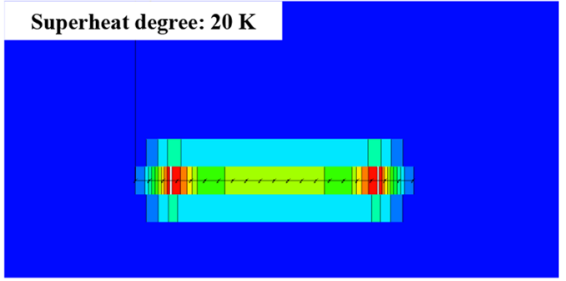

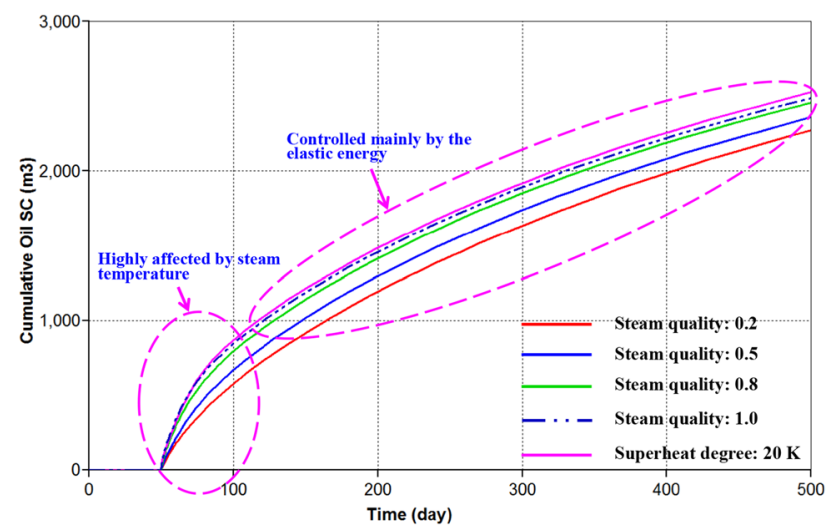

Fig. 8 Comparison of the oil production rate under saturated or superheated steam injection (Xu et al. 2013)

and the mobility is increased. However, after 100 days, the curves coincide with each other, and, at this stage, the elastic energy becomes the dominant factor controlling the productivity of the oil well. Second, the pink curve, representing superheated steam injection, coincide with the blue dotted curve at even the beginning stage with only small increase in oil production rate at the first 10 days. These figures proves that, compared with chemical reactions, the physical heating effect of superheated steam on well productivity is weak. Now, it is clear that the main factors contributed to the increase shown in Fig. 8 are the chemical reactions of superheated steam with heavy oil and rock minerals.

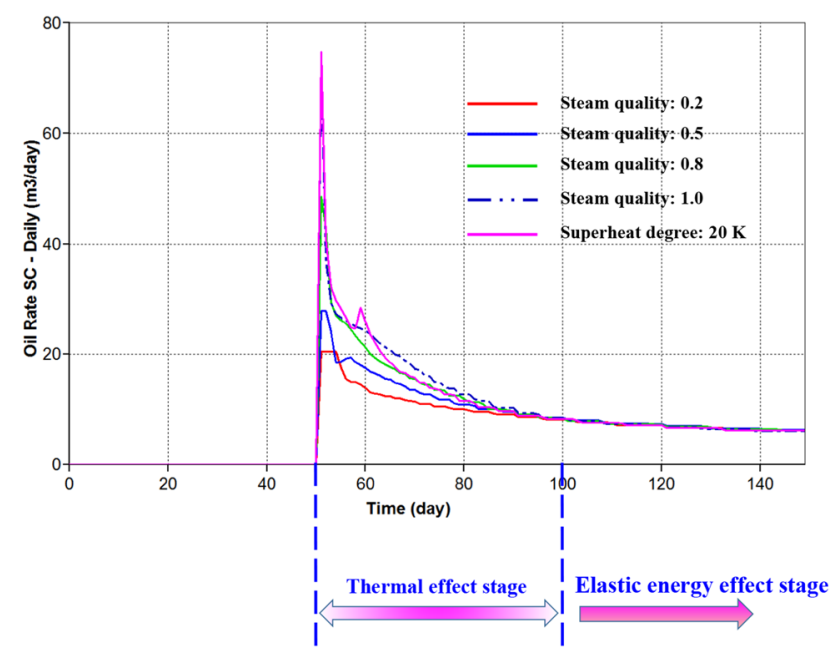

Fig. 9 Daily oil production rate under different steam state conditions

\section{Conclusions}

In this paper, the contribution of physical heating of superheated steam on well productivity is studied with numerical method. Some meaningful conclusions are listed below:

(a) The heat in the area has a very limited increase when the temperature of superheated steam continues to increase.

(b) At the starting stage, the oil is heated to a higher temperature and the mobility is increased. The elastic 
energy becomes the dominant factor controlling the productivity of the oil well in the following stage.

(c) The chemical reactions of superheated steam with oil and rock minerals are the dominant factors contributing to the productivity.

\begin{abstract}
Acknowledgements The research was supported by National Science and Technology Major Projects of China (nos. 2016ZX05042, 2017ZX05039 and 2016ZX05039) and the National Natural Science Foundation Projects of China (nos. 51504269, 51490654 and 40974055). The authors also acknowledge Science Foundation of China University of Petroleum, Beijing (no. C201605), the National Basic Research Program of China (2015CB250900), the Program for New Century Excellent Talents in University (Grant no. NCET-131030) to support part of this work.
\end{abstract}

Open Access This article is distributed under the terms of the Creative Commons Attribution 4.0 International License (http://creativeco mmons.org/licenses/by/4.0/), which permits unrestricted use, distribution, and reproduction in any medium, provided you give appropriate credit to the original author(s) and the source, provide a link to the Creative Commons license, and indicate if changes were made.

\section{References}

Arab D, Kantzas A, Bryant SL (2018) Nanoparticle stabilized oil in water emulsions: a critical review. J Pet Sci Eng 163:217-242

Babadagli T, Cao N (2018) An experimental study to determine suitable injection strategies for water-alternating-solvent process in green and brownfields. J Pet Sci Eng 165:136-150

Calder J, Roy MM, Wang W (2018) Performance and emissions of a diesel engine fueled by biodiesel-diesel blends with recycled expanded polystyrene and fuel stabilizing additive. Energy 149:204-212

Dabirian R, Padsalgikar A, Mohan RS, Shoham O (2018) Four-layer model for prediction of sand bed height in horizontal gas-liquid stratified flow. J Pet Sci Eng 165:151-160

Duan CW, Hu LX, Ma JL (2018) Ionic liquids as an efficient medium for the mechanochemical synthesis of $\alpha-\mathrm{AlH} 3$ nano-composites. J Mater Chem A 6:6309-6318

Feng D, Li X, Wang X, Li J, Zhang X (2018a) Capillary filling under nanoconfinement: the relationship between effective viscosity and water-wall interactions. Int J Heat Mass Transf 118:900-910

Feng D, Li X, Wang X et al (2018b) Water adsorption and its impact on the pore structure characteristics of shale clay. Appl Clay Sci 155:126-138

Feng D, Li XF, Wang XZ, Li J, Zhang T, Sun Z, He MX, Liu Q, Qin JZ, Han S (2018c) Capillary filling of confined water in nanopores: coupling the increased viscosity and slippage. Chem Eng Sci $186: 228-239$

Fu H, Liu X (2017a) Research on the phenomenon of Chinese residents' spiritual contagion for the reuse of recycled water based on SC-IAT. Water 9:846

Fu H, Liu X (2017b) A study on the impact of environmental education on individuals' behaviors concerning recycled water reuse. Eurasia J Math Sci Technol Educ 13:6715-6724

Fu H, Li Z, Liu Z, Wang Z (2018) Research on big data digging of hot topics about recycled water use on micro-blog based on particle swarm optimization. Sustainability 10:2488. https://doi. org/10.3390/su10072488
Gao CH (2018) Experiences of microbial enhanced oil recovery in Chinese oil fields. J Pet Sci Eng 166:55-62

Gerevini GG, Farenzena M, Trierweiler JO (2018) Slugging attenuation using nonlinear model predictive control in offshore oil production. J Pet Sci Eng 165:187-198

Hu XD, Wu K, Li GS, Tang JZ, Shen ZH (2018a) Effect of proppant addition schedule on the proppant distribution in a straight fracture for slickwater treatment. J Pet Sci Eng 167:110-119

Hu XD, Song XZ, Li GS (2018b) An analytical model to evaluate the heating conditions for drilling in hard rock using an innovative hydrothermal spallation method. Appl Therm Eng 142: 709-716

Hu XD, Song XZ, Li GS (2018c) Shape factor of the flake-like particle in thermal spallation and its effects on settling and transport behavior in drilling annulus. Powder Technol 335:211-221

Huang SJ, Cao M, Cheng LS (2018a) Experimental study on aquathermolysis of different viscosity heavy oil with superheated steam. Energy Fuels 32(4):4850-4858

Huang SJ, Cao M, Xia Y, Chen X, Yang ML (2018b) Heat and mass transfer characteristics of steam in a horizontal wellbore with multi-point injection technique considering wellbore stock liquid. Int J Heat Mass Transf 127:949-958

Livescu S, Craig S (2018) A critical review of the coiled tubing friction-reducing technologies in extended-reach wells. Part 2: vibratory tools and tractors. J Pet Sci Eng 166:44-54

Sheikholeslami M (2017a) Lattice Boltzmann method simulation of MHD non-Darcy nanofluid free convection. Phys B 516:55-71

Sheikholeslami M (2017b) Influence of magnetic field on nanofluid free convection in an open porous cavity by means of Lattice Boltzmann Method. J Mol Liq 234:364-374

Sheikholeslami M (2017c) Magnetohydrodynamic nanofluid forced convection in a porous lid driven cubic cavity using Lattice Boltzmann Method. J Mol Liq 231:555-565

Sheikholeslami M (2017d) Numerical investigation of MHD nanofluid free convective heat transfer in a porous tilted enclosure. Eng Comput 34(6): 1939-1955

Sheikholeslami M (2017e) Magnetic field influence on nanofluid thermal radiation in a cavity with tilted elliptic inner cylinder. J Mol Liq 229:137-147

Sheikholeslami M (2017f) Numerical simulation of magnetic nanofluid natural convection in porous media. Phys Lett A 381:494-503

Sheikholeslami M (2017g) Influence of Lorentz forces on nanofluid flow in a porous cylinder considering Darcy model. J Mol Liq 225:903-912

Sheikholeslami M (2017h) Influence of Coulomb forces on $\mathrm{Fe}_{3} \mathrm{O}_{4}$ $\mathrm{H}_{2} \mathrm{O}$ nanofluid thermal improvement. Int J Hydrog Energy 42:821-829

Sheikholeslami M (2018a) Influence of magnetic field on $\mathrm{Al}_{2} \mathrm{O}_{3}-\mathrm{H}_{2} \mathrm{O}$ nanofluid forced convection heat transfer in a porous lid driven cavity with hot sphere obstacle by means of LBM. J Mol Liq 263:472-488

Sheikholeslami M (2018b) Numerical simulation for solidification in a LHTESS by means of nano-enhanced PCM. J Taiwan Inst Chem Eng 86:25-41

Sheikholeslami M (2018c) Numerical modeling of nano enhanced PCM solidification in an enclosure with metallic fin. J Mol Liq 259:424-438

Sheikholeslami M (2018d) CuO-water nanofluid flow due to magnetic field inside a porous media considering Brownian motion. J Mol Liq 249:921-929

Sheikholeslami M (2018e) Numerical investigation of nanofluid free convection under the influence of electric field in a porous enclosure. J Mol Liq 249:1212-1221

Sheikholeslami M (2018f) Numerical investigation for $\mathrm{CuO}-\mathrm{H}_{2} \mathrm{O}$ nanofluid flow in a porous channel with magnetic field using mesoscopic method. J Mol Liq 249:739-746 
Sheikholeslami M, Shehzad SA (2018h) Simulation of water based nanofluid convective flow inside a porous enclosure via nonequilibrium model. Int J Heat Mass Transf 120:1200-1212

Sheikholeslami M, Shamlooei M, Moradi R (2018g) Fe $\mathrm{O}_{4}$-ethylene glycol nanofluid forced convection inside a porous enclosure in existence of Coulomb force. J Mol Liq 249:429-437

Shi J, Li X, Li Q, Wang F, Sepehrnoori K (2014) Gas permeability model considering rock deformation and slippage in low permeability water-bearing gas reservoirs. J Pet Sci Eng 120:61-72

Shi J, Li X, Cheng S, Zhou J, Gao B (2015a) A new approach for evaluating well deliverability in ultra-thick gas reservoirs. J Pet Sci Eng 133:869-880

Shi J, Huang L, Li X, Sepehrnoori K (2015b) Production forecasting of gas condensate well considering fluid phase behavior in the reservoir and wellbore. J Nat Gas Sci Eng 24:279-290

Shi J, Chang Y, Wu S, Xiong X, Liu C, Feng K (2018) Development of material balance equations for coalbed methane reservoirs considering dewatering process, gas solubility, pore compressibility and matrix shrinkage. Int J Coal Geol 195:200-216

Struchkov IA, Rogachev MK (2018) The challenges of waxy oil production in a Russian oil field and laboratory investigations. J Pet Sci Eng 163:91-99

Sun FR, Yao YD, Li XF, Yu PL, Ding GY, Zou M (2017a) The flow and heat transfer characteristics of superheated steam in offshore wells and analysis of superheated steam performance. Comput Chem Eng 100:80-93

Sun FR, Yao YD, Chen MQ, Li XF, Zhao L, Meng Y, Sun Z, Zhang T, Feng D (2017b) Performance analysis of superheated steam injection for heavy oil recovery and modeling of wellbore heat efficiency. Energy 125:795-804

Sun FR, Yao YD, Li XF, Yu PL, Zhao L, Zhang Y (2017c) A numerical approach for obtaining type curves of superheated multi-component thermal fluid flow in concentric dual-tubing wells. Int J Heat Mass Transf 111:41-53

Sun FR, Yao YD, Li XF, Zhao L (2017d) Type curve analysis of superheated steam flow in offshore horizontal wells. Int J Heat Mass Transf 113:850-860

Sun FR, Yao YD, Li XF, Zhao L, Ding GY, Zhang XJ (2017e) The mass and heat transfer characteristics of superheated steam coupled with non-condensing gases in perforated horizontal wellbores. J Pet Sci Eng 156:460-467

Sun FR, Yao YD, Li XF, Tian J, Zhu GJ, Chen ZM (2017f) The flow and heat transfer characteristics of superheated steam in concentric dual-tubing wells. Int J Heat Mass Transf 115:1099-1108

Sun FR, Yao YD, Li XF, Li H, Chen G, Sun Z (2017g) A numerical study on the non-isothermal flow characteristics of superheated steam in ground pipelines and vertical wellbores. J Pet Sci Eng 159:68-75

Sun FR, Yao YD, Li XF (2017h) Numerical simulation of superheated steam flow in dual-tubing wells. J Pet Explor Prod Technol. https ://doi.org/10.1007/s13202-017-0390-7

Sun FR, Yao YD, Li XF (2017i) Effect of gaseous $\mathrm{CO}_{2}$ on superheated steam flow in wells. Eng Sci Technol Int J 20(6):1579-1585

Sun FR, Yao YD, Li XF (2017j) Effect analysis of non-condensable gases on superheated steam flow in vertical single-tubing steam injection pipes based on the real gas equation of state and the transient heat transfer model in formation. J Pet Explor Prod Technol. https://doi.org/10.1007/s13202-017-0419-y

Sun FR, Yao YD, Li XF (2018a) The heat and mass transfer characteristics of superheated steam coupled with non-condensing gases in horizontal wells with multi-point injection technique. Energy 143:995-1005

Sun FR, Yao YD, Li XF, Li GZ, Chen ZL, Chang YC, Cao M, Han S, Lv CH, Feng D, Sun Z (2018b) Effect of flowing seawater on supercritical $\mathrm{CO}_{2}$-superheated water mixture flow in an offshore oil well considering the distribution of heat generated by the work of friction. J Pet Sci Eng 162:460-468

Sun FR, Yao YD, Li XF, Li GZ, Miao YN, Han S, Chen ZL (2018c) Flow simulation of the mixture system of supercritical $\mathrm{CO}_{2} \&$ superheated steam in toe-point injection horizontal wellbores. J Pet Sci Eng 163:199-210

Sun FR, Yao YD, Li XF, Li GZ, Sun Z (2018d) A numerical model for predicting distributions of pressure and temperature of superheated steam in multi-point injection horizontal wells. Int J Heat Mass Transf 121:282-289

Sun FR, Yao YD, Li XF, Li GZ, Huang L, Liu H, Chen ZL, Liu H, Liu WY, Cao M, Han S (2018e) Exploitation of heavy oil by supercritical $\mathrm{CO}_{2}$ : effect analysis of supercritical $\mathrm{CO}_{2}$ on $\mathrm{H}_{2} \mathrm{O}$ at superheated state in integral joint tubing and annuli. Greenh Gases Sci Technol 8(3):557-569

Sun FR, Yao YD, Li XF, Li GZ, Liu Q, Han S, Zhou YJ (2018f) Effect of friction work on key parameters of steam at different state in toe-point injection horizontal wellbores. J Pet Sci Eng 164:655-662

Sun FR, Yao YD, Li XF, Li GZ, Han S, Liu Q, Liu WY (2018g) Type curve analysis of multi-phase flow of multi-component thermal fluid in toe-point injection horizontal wells considering phase change. J Pet Sci Eng 165:557-566

Sun F, Yao Y, Li G, Li X, Chen M, Chen G, Zhang T (2018h) Analysis of superheated steam performance in offshore concentric dualtubing wells. J Pet Sci Eng 166:984-999

Sun F, Yao Y, Li G, Li X, Lu C, Chen Z (2018i) A model for predicting thermophysical properties of water at supercritical state in offshore CDTW. Measurement 124:241-251

Sun F, Yao Y, Li G, Li X, Zhang T, Lu C, Liu W (2018j) An improved two-phase model for saturated steam flow in multi-point injection horizontal wells under steady-state injection condition. J Pet Sci Eng 167:844-856

Sun F, Yao Y, Li G, Li X, Li Q, Yang J, Wu J (2018k) A coupled model for $\mathrm{CO}_{2} \&$ superheated steam flow in full-length concentric dualtube horizontal wells to predict the thermophysical properties of $\mathrm{CO}_{2}$ \& superheated steam mixture considering condensation. J Pet Sci Eng 170:151-165

Sun F, Yao Y, Li X (20181) The heat and mass transfer characteristics of superheated steam in horizontal wells with toe-point injection technique. J Pet Explor Prod Technol. https://doi.org/10.1007/ s13202-017-0407-2

Sun F, Yao Y, Li X, Li G (2018m) A brief communication on the effect of seawater on water flow in offshore wells at supercritical state. J Pet Explor Prod Technol. https://doi.org/10.1007/s1320 2-018-0456-1

Sun F, Yao Y, Li X, Li G (2018n) An analytical equation for oil transport in nanopores of oil shale considering viscosity distribution. J Pet Explor Prod Technol. https://doi.org/10.1007/s13202-018-0486-8

Sun F, Yao Y, Li G (2018o) New analytical equations for productivity estimation of the cyclic $\mathrm{CO}_{2}$-assisted steam stimulation process considering the non-Newtonian percolation characteristics. J Pet Explor Prod Technol. https://doi.org/10.1007/s13202-018-0518-4

Sun F, Yao Y, Li G, Zhao L, Liu H, Li X (2018p) Water performance in toe-point injection wellbores at supercritical state. In: SPE trinidad and tobago section energy resources conference, SPE191151-MS, 25-26 June 2018 in Port of Spain, Trinidad and Tobago. https://doi.org/10.2118/191151-MS

Sun F, Yao Y, Li G, Feng N, Zhang S, Huang L, Li X (2018q) A numerical model for simulating supercritical water flow in perforated horizontal wellbores. In: SPE Kingdom of Saudi Arabia annual technical symposium and exhibition, SPE-KSA-, 23-26 April 2018 in Dammam, Saudi Arabia

Sun F, Yao Y, Li G, Li X, Sun J (2018r) Comparison of steam front shape during steam flooding process under varying steam state condition: numerical analysis. In: Abu Dhabi international

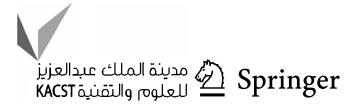


petroleum exhibition and conference, SPE-192996-MS, 12-15 November, Abu Dhabi, UAE

Sun F, Yao Y, Li G, Li X (2018s) Performance of geothermal energy extraction in a horizontal well by using $\mathrm{CO}_{2}$ as the working fluid. Energy Convers Manag 171:1529-1539

Sun F, Yao Y, Li G, Li X (2018t) Geothermal energy extraction in $\mathrm{CO}_{2}$ rich basin using abandoned horizontal wells. Energy 158:760-773

Wang B, Qin Y, Shen J, Zhang Q, Wang G (2018) Pore structure characteristics of low- and medium-rank coals and their differential adsorption and desorption effects. J Pet Sci Eng 165:1-12

Wen J, Zhang B, Xu Y, Yang J, Han N (2018a) Adaptive weighted nonnegative low-rank representation. Pattern Recogn 81:326-340

Wen J, Xu Y, Li Z, Ma Z, Xu Y (2018b) Inter-class sparsity based discriminative least square regression. Neural Netw 102:36-47

Xiong H, Wu Y (2018) Optomechanical akhmediev breathers. Laser Photonics Rev 12(7):1700305

Xu AZ, Mu LX, Fan ZF, Wu XH, Zhao L, Bo B et al (2013) Mechanism of heavy oil recovery by cyclic superheated steam stimulation. J Pet Sci Eng 111:197-207

Yang J, Li X, Chen Z, Tian J, Huang L, Li Y (2018) A productivity model for cyclic steam stimulation for heavy oil with non-Newtonian flow behaviour. Int J Oil Gas Coal Technol 17(3):257-283

Yin K, Du HF, Dong XR, Wang C, Duan JA, He J (2017) A simple way to achieve bioinspired hybrid wettability surface with micro/nanopatterns for efficient fog collection. Nanoscale 9:14620-14626

Yin K, Yang S, Dong X, Chu D, Duan J-A, He J (2018) Robust laserstructured asymmetrical PTFE mesh for underwater directional transportation and continuous collection of gas bubbles. Appl Phys Lett 112:243701
Zhang T, Li X, Sun Z, Feng D, Miao Y, Li P, Zhang Z (2017a) An analytical model for relative permeability in water-wet nanoporous media. Chem Eng Sci 174:1-12

Zhang T, Li X, Li J, Feng D, Li P, Zhang Z, Chen Y, Wang S (2017b) Numerical investigation of the well shut-in and fracture uncertainty on fluid-loss and production performance in gas-shale reservoirs. J Nat Gas Sci Eng 46:421-435

Zhang SK, Huang ZW, Li GS, Wu XG, Peng C, Zhang WP (2018a) Numerical analysis of transient conjugate heat transfer and thermal stress distribution in geothermal drilling with high-pressure liquid nitrogen jet. Appl Therm Eng 129:1348-1357

Zhang S, Huang Z, Huang P, Wu X, Xiong C, Zhang C (2018b) Numerical and experimental analysis of hot dry rock fracturing stimulation with high-pressure abrasive liquid nitrogen jet. J Pet Sci Eng 163:156-165

Zhang S, Huang Z, Wang H, Zhang H, Zhang C, Xiong C (2018c) Thermal characteristics analysis with local thermal non-equilibrium model during liquid nitrogen jet fracturing for HDR reservoirs. Appl Therm Eng 143:482-492

Zhou TY (2010) Mechanism study of heavy oil exploitation with superheated steam injection (Doctoral Dissertation). China University of Petroleum, Beijing

Zhou TY, Cheng LS, Li CL, Zhu SF, Guo CS (2009) Experiment of Aquathermolysis reaction between heavy oil and over-heated steam. J Southwest Pet Univ (Sci Technol Ed) 31(6):89-92

Publisher's Note Springer Nature remains neutral with regard to jurisdictional claims in published maps and institutional affiliations. 